\title{
Anacronias da crítica literária em jornal: a transição da matriz romântica ao rodapé
}

Anachronism of literary criticism in newspaper: the transition from romanticism matrix to 'rodapé' criticism

Anacronismo de la crítica literaria en periódico: la transición de la matriz del romanticismo a la crítica de 'rodapé'

DOI: https://doi.org/10.1590/1809-5844202013

\author{
Rachel Bertol ${ }^{1}$ \\ https://orcid.org/0000-0001-8411-4002
}

${ }^{1}$ (Universidade Federal Fluminense, Instituto de Arte e Comunicação Social, Departamento de Comunicação. Rio de Janeiro - RJ, Brasil).

\section{Resumo}

Tema pouco explorado na área da Comunicação, a crítica literária, no entanto, ocupou lugar de destaque na cultura jornalística em período no qual a literatura também desfrutava de grande prestígio na sociedade. O artigo tem como objetivo analisar a crítica literária em conjunção com a atividade jornalística no Brasil, a partir de três momentos: o que chamamos de "matriz romântica", a consolidação na virada do século XIX ao XX, até a invenção da "crítica de rodapé" na primeira metade do século passado. Em termos metodológicos, toma-se como base o conceito de "rede discursiva" desenvolvido por Kittler, que auxilia na compreensão sobre as origens da crítica no Romantismo e sobre como os jornais valorizam determinados tipos de articulação textual em diferentes períodos. Desse modo, busca-se lançar luz sobre um processo ainda pouco estudado, ao se observar uma clivagem entre a crítica e a reportagem, que no ambiente das mídias digitais passa por novas reconfigurações.

Palavras-chave: crítica literária. crítica de rodapé. José Veríssimo. Romantismo. História do jornalismo.

\begin{abstract}
Literary criticism is a topic rarely explored in the Communication field, although it occupied a prominent role in the journalistic culture in a period in which literature also enjoyed great prestige in society. This article aims to analyze literary criticism in conjunction with the journalistic activity in Brazil, in three moments: what we call the "romanticism matrix"; the consolidation at the turn of the 19th and 20th centuries; the invention of what was known as "Footer criticism" in the first half of last century. In methodological terms, the concept of discourse networks, by Kittler, helps to
\end{abstract}


understand the origins of criticism in Romanticism and on how newspapers value certain types of textual articulation in different periods. The aim is to shed light on a process that has not yet been studied, especially the cleavage observed between criticism and report, which in the digital media environment undergoes new reconfigurations.

Key words: literary criticism. footer criticism. José Veríssimo. Romanticism. Journalism History.

\section{Resumen}

A pesar de ser un tema poco explorado en la Comunicación, la crítica literaria ocupaba un lugar destacado en la cultura periodística en un tiempo en que la literatura también disfrutaba de gran prestigio en la sociedad. El presente artículo tiene como objetivo analizar la crítica literaria en conjunción con la actividad periodística en Brasil, a partir de tres momentos: lo que llamamos “matriz romántica”; la consolidación a la vuelta del siglo XIX al XX; la invención de la "crítica de rodapié" en la primera mitad del siglo pasado. En términos metodológicos, se toma como base el concepto de red discursiva desarrollado por Kittler, que auxilia en la comprensión sobre los orígenes de la crítica en el Romanticismo y sobre cómo los periódicos valorizan tipos de articulación textual en diferentes períodos. Se busca lanzar luz sobre un proceso poco estudiado, al observarse una brecha entre la crítica y el reportaje, que en el ambiente de los medios digitales pasa por reconfiguraciones. Palabras clave: crítica literaria. crítica de rodapié. José Veríssimo. Romanticismo. Historia del periodismo.

\section{Introdução}

A crítica literária praticada em jornal constitui-se em objeto de pesquisa pouco explorado nas pesquisas realizadas na área de Comunicação. Sendo um tema mais comum no campo de Letras, neste, entretanto, não se costuma observar as conjunções relacionadas às demandas específicas dos jornais que publicavam inicialmente os textos. Num período em que a literatura contava com grande prestígio na sociedade, como no século XIX, a crítica literária, publicada nos jornais, por conseguinte, também desempenhava papel de destaque na cultura jornalística. Trata-se de uma proeminência que se alongou pelo século $\mathrm{XX}$ (embora reconfigurada, como veremos ao longo do texto).

O fato de o tema até o momento ainda não ter despertado interesse significativo na Comunicação pode se explicar, em parte, pela ênfase das pesquisas a respeito da atividade de reportagem e da figura do repórter. Uma ênfase certamente justificada e necessária, no que se refere à consolidação das pesquisas comunicacionais, com o desenvolvimento de metodologias próprias, buscando dar conta de demandas (inclusive pedagógicas) que outras áreas (como a História) não conseguiam suprir.

Nesse movimento, entretanto, outras figuras que compunham o universo dos jornais acabaram (inevitavelmente) ficando de lado. O autor do "artigo de fundo", por exemplo, que tinha como objetivo dar sustentação e amarrar os demais textos do jornal, acabou passando para o "fundo" de fato. No entanto, atualmente, em um novo momento das pesquisas históricas 
a respeito da imprensa, sugere-se a reintegração dessas figuras ao âmbito jornalístico, sem prejuízo ao repórter.

Certamente, as transformações proporcionadas pelas tecnologias digitais ajudam na compreensão dessa proposta, na medida em que a reportagem vem sendo deslocada do espaço a que se circunscreveu pelo menos desde meados do século passado. Novas perguntas, sobre experiências linguísticas variadas, começam necessariamente a ser formuladas não apenas sobre a contemporaneidade, como acerca da história do jornalismo. A opinião ${ }^{1}$ foi vertente deixada de lado no momento em que o campo se encontrava envolvido, pelo menos desde meados do século passado, com a construção de premissas relacionadas à ideia de objetividade $^{2}$. No entanto, a opinião é tópico que retorna com força à cena jornalística. Portanto, dar nova atenção à maneira como se configurou historicamente nos jornais a atividade de crítica literária, cuja articulação também difere da reportagem, pode fornecer subsídios para a ampliação do debate sobre as linguagens constitutivas do jornalismo para além da reportagem (e em conjunção com esta).

Neste artigo, será tomado como ponto de partida a participação na imprensa do crítico José Veríssimo (1857-1916). Com Sílvio Romero e Araripe Jr., Veríssimo forma a tríade que, nos estudos literários, é considerada a fundadora da tradição da crítica literária brasileira no século XX. Entre esses, Veríssimo teve maior presença na imprensa republicana, por isso ganha relevo para o atual propósito. O período de sua atuação, na virada do século XIX ao $\mathrm{XX}$, na chamada belle époque tropical, será o eixo de articulação a partir do qual se evidencia uma espécie de anacronia da crítica literária em jornal e a passagem do que chamamos de “matriz romântica” para a "crítica de rodapé”, que irá se consolidar na imprensa do país por volta dos anos 1930.

Logo uma primeira pergunta se impõe: o que se quer dizer com matriz romântica? O trabalho vai se organizar a partir de três tempos: no centro, o eixo articulador, na virada do século XIX ao XX; como base, anteriormente, o tempo que forma a matriz romântica; por fim, o da crítica de rodapé, que se estabelece no Brasil a partir dos anos 1920-30.

\footnotetext{
1 Estudo de Marques de Melo (1994) é dos poucos a considerar a opinião um gênero do jornalismo brasileiro. A questão dos gêneros jornalísticos, em geral tomando no Brasil como ponto de partida a proposição de Melo, tem sido retomada nos últimos anos, devido, em parte, às reconfigurações propostas pelas novas formas de circulação da informação nos ambientes virtuais.

2 A questão da objetividade construída como projeto geracional de jornalistas, nos anos 1950, que tinha como base uma construção textual com lastro na reportagem é analisada amplamente por Ribeiro (2007), incluindo ainda aspectos relacionados à profissionalização industrial e a constituição dos primeiros cursos de jornalismo. Barbosa (1996, 2007, 2010) realiza ampla pesquisa sobre como o campo jornalístico começa a se estruturar na virada do século XIX para o XX. Seu trabalho pioneiro e de fôlego a respeito da história dos processos comunicacionais relacionados ao jornalismo abrange aspectos da prática e da sua origem. Já Sodré (1999), em seu estudo clássico, também fornece subsídios imprescindíveis sobre a história do jornalismo e da imprensa brasileira até meados do século passado. No seu caso (marcado pela análise das relações de produção a partir de um viés marxista), assim como no de Barbosa (que parte de autores como Darnton, Chartier, Ricoeur), analisam-se os processos em suas linhas de força. Aqui, o objetivo é mais específico, ao se buscar realizar a análise das conjunções da crítica literária no espaço jornalístico. Não que se seja tema ignorado, mas como tema específico para estudo dentro do campo jornalístico e comunicacional, a crítica literária não costuma ser objeto de atenção nas pesquisas da área.
} 


\section{Matriz romântica}

Como o nome indica, a ideia de "matriz romântica” relaciona-se ao período do romantismo, em sua origem, na virada do século XVIII ao XIX. Pode-se dizer que há praticamente um consenso nos estudos do tema que indicam o nascimento da crítica literária, em seu formato moderno, com o romantismo. De certa forma, ela seria um subproduto deste. Kittler (1990), teórico das mídias que busca compreender as condições que levaram ao surgimento da crítica literária no contexto alemão, relaciona essa modalidade de linguagem ao escopo maior do que denomina "crítica hermenêutica”. A maneira como Kittler (1990) aborda a questão, a partir da realidade de seu país, é aqui particularmente cara, pois o romantismo possui fortes raízes alemãs ${ }^{3}$ e influenciou a difusão do movimento por toda a Europa e mesmo por todo o mundo. Digamos que há no território alemão uma matriz (para se usar desde já a expressão destacada no título).

Ao reconstituir os circuitos do que chama "crítica hermenêutica”, no período em que ocorre pela primeira vez a alfabetização em massa, no século XIX, Kittler (1990) ao mesmo tempo aponta para a finitude dessa crítica. No momento de formação dos Estados nacionais, passa-se a ler a literatura alemã nas escolas e a poesia substitui a Bíblia. A letra do poeta, como a de Goethe, central em sua reconstituição, adquire ela própria sacralidade. Pontuando a rede discursiva, tem-se a função da Mulher, igualada à Natureza. Trata-se da mãe, professora caseira das primeiras letras, ainda que a escrita e a publicação lhe sejam negadas (o circuito das publicações dos homens de letras, diz Kittler, era homossexual ${ }^{4}$ ). Mas a Mulher é aquela para quem se escreve, a razão de ser do poeta. Assim se origina a “rede discursiva 1800”: pela boca da mãe que nina seu filho com cantigas imemoriais.

Aos poucos, o sistema universitário se desenvolve, primeiramente visando a formar quadros para as novas burocracias estatais. Nasce a tradição do ensaio - e da hermenêutica - na educação alemã desde os anos do ginasial. O ensino formal das meninas também é reforçado: elas precisam ser preparadas para a função de mães e para alfabetizar os filhos. Educação (Bildung) torna-se uma palavra-chave. O mercado editorial se caracteriza, pela primeira vez, pelo excesso: há uma "mania” de leitura, especialmente entre as moças, que se considera salutar temperar. Esse excesso torna-se uma característica importante. Diante dele, desenvolvem-se mecanismos de seleção pela crítica, pelas antologias, pelo ensino, com a formação de conjuntos de obras consideradas canônicas. A consolidação dos direitos de autor também se destaca para a organização dos mecanismos editoriais.

\footnotetext{
3 A preponderância alemã é notória. O romantismo alemão foi pioneiro e se impôs ainda antes do movimento na França. Candido faz uma referência bem-humorada a essa base alemã para o caso brasileiro. Em 1836, um grupo de brasileiros reunidos em Paris, sob o comando de Gonçalves de Magalhães, lançou a revista Niterói, Revista Brasiliense de Ciências, Letras e Artes, que, apesar de ter sobrevivido apenas dois números, se tornou ponto de partida para o romantismo e o nacionalismo literário. "Estava lançada a cartada, fundindo medíocre, mas fecundamente, para uso nosso, o complexo Schlegel-Staël-Humboldt-Chateaubriand-Denis” (CANDIDO, [1957]2006, p. 331).

4 Gumbrecht (2013) observa que Kittler incorpora uma consideração pragmática da diferença sexual para sua abordagem da história.
} 
Os documentos empíricos são fundamentais para a reconstituição das redes discursivas. O arquivo com que Kittler (1990) trabalha compreende a própria literatura (por dentro), especialmente Fausto, de Goethe; uma grande variedade de material epistolar, especialmente de escritores; cartilhas de alfabetização; despachos administrativos; programas educacionais; obras filosóficas, entre outros. O poeta é a outra face da moeda em que aparece o funcionário público - um precisa do outro e a rede discursiva se constitui com os dois.

O romantismo, nesse quadro, torna-se uma tecnologia da letra ${ }^{5}$ Kittler (1990) não o analisa como se fosse uma ideologia que propicia uma noção da autonomia artística, a voz original do gênio, a expressão singular da imaginação criativa para além da realidade, o encontro com a totalidade. Não que negue a ideologia, mas ele quer se situar num estágio anterior a esta. Os elementos que busca, a partir de uma perspectiva de materialidade da comunicação, conceito que Gumbrecht e seu grupo (GUMBRECHT; PFEIFFER, 1994) desenvolveram na segunda metade dos anos 1980 a partir de Kittler (1990) ${ }^{6}$, compõem o que ele denomina de "rede discursiva" (discourse network, segundo a tradução americana do alemão de Aufschreimesysteme). Por meio desse conceito, ele quer observar a maneira como se organiza a possibilidade da comunicação num determinado momento e contexto histórico. O objetivo, numa primeira etapa do seu trabalho, é apresentar as condições que propiciaram a formação da "rede discursiva 1800", quando surgem o romantismo e o idealismo alemão, período que em seguida ele irá comparar à “rede discursiva 1900”, a partir da virada do século XIX ao XX.

Enquanto tecnologia da letra, o romantismo vale-se de recursos tecnológicos diversos, como a crítica literária. A esse respeito, conforme já apontamos, existe praticamente um consenso: é com o romantismo que nasce a crítica literária tal como ela se desenvolveu (com variações, decerto) a seguir. José Veríssimo, em sua História da literatura brasileira, já dava ênfase a esse momento originário:

A crítica como um ramo independente da literatura, o estudo das obras com um critério mais largo que as regras da retórica clássica, e já acompanhando de indagações psicológicas e referências mesológicas, históricas e outras, buscando compreender-lhes e explicar-lhes a formação e essência, essa crítica derivada aliás imediatamente daquela, pelo que lhe conservou alguma das feições mais antipáticas, nasceu com o Romantismo (VERÍSSIMO, 1998 [1916], p. 384).

5 A visão com que Killter propõe seu conceito de mídia encontra um paralelo em Walter Benjamin. “O único crítico ou teórico que eu conheço que vê a significância histórica da mídia numa forma similarmente radical é Walter Benjamin” (WELLBERY, 1990, p. XXXI apud KITTLER, 1990 -Tradução livre). Do inglês: "The only critic ou theoretician I know who views the historical significance of the media in a similarly radical way is Walter Benjamin".

6 O livro clássico de Kittler, Aufschreimesysteme, é de 1985 e foi traduzido nos EUA para o inglês em 1990 com o título Discourse networks, obra que tomamos como base. O livro é inédito em português. 
Para além das ideias, há com a crítica literária uma forma de “articulação textual” que se põe em marcha. Prendergast (2007, p. 8) destaca que o crítico francês Sainte-Beuve (18041864) não chegou a usar o termo hermenêutica, porém estava, "mesmo que de passagem”, ciente do trabalho do alemão Friedrich Schleiermacher, considerado o pai da hermenêutica no romantismo alemão. Em Sainte-Beuve, a interpretação começava com uma "conversa" (causerie) que demanda o exercício de escuta por parte do crítico - em 1859, ele começou a escrever no jornal francês Le Constitutionnel a sua influente coluna semanal de crítica literária intitulada Les causeries du Lundi (As conversas de segunda-feira). Ouvir o outro seria um movimento de empatia, com o objetivo de abolir não a diferença, mas a distância, na busca de uma "crítica neutra” para pôr em consideração o ponto de vista e o universo estilístico de um determinado autor. Sainte-Beuve, que integrou o círculo romântico em torno de Victor Hugo, foi “o principal crítico profissional da França” em seu tempo, protótipo do intelectual público, uma autoridade que criava valores e influenciou os leitores "pelo medium do jornalismo literário” (PRENDERGAST, 2007, p. 17). A sua autoridade intelectual seria derivada - sob a perspectiva das proposições levantadas por Kittler (1990) - da valorização da crítica hermenêutica ensejada pela “rede discursiva 1800”.

Pode-se dizer que Sainte-Beuve, pelo grande poder que concentrou, se tornou uma referência da atividade da crítica literária profissional na imprensa. Isso seria válido, inclusive, para Veríssimo, embora o crítico tenha sofrido a influência de muitos outros pensadores, com vivências diversas daquelas do romantismo, sendo Machado de Assis seu principal interlocutor literário. No Brasil, onde a influência da cultura francesa se fazia decisiva, Sainte-Beuve era figura bastante conhecida (ainda antes da fase no Le Constitutionnel), quando escrevia na influente La Revue des Deux Mondes, muito lida no país. A crítica que exercia teria uma “matriz romântica”, que se define, portanto, por uma forma de articulação textual calcada na hermenêutica que o movimento romântico demandava.

\section{Crítica vs. reportagem}

É preciso ir ao arquivo de periódicos para compreender como surgiu a participação de José Veríssimo como crítico literário na imprensa do Rio de Janeiro (exercício que, apesar de simples, poucas vezes se faz; em geral, os estudos das críticas de Veríssimo baseiam-se sobretudo nas coletâneas de seus textos organizadas por ele próprio ${ }^{7}$ ). Natural de Óbidos, no Pará, o crítico já era personalidade intelectual em Belém quando se mudou para o Rio em 1891, pouco menos de dois anos depois de proclamada a República. Em 1890, havia

\footnotetext{
7 Em vida, Veríssimo publicou seus textos de imprensa em duas séries denominadas Estudos brasileiros; seis séries de Estudos de literatura brasileira; e três que intitulou Homem e coisas estrangeiras (embora isso tudo corresponda a apenas uma parcela de sua participação em jornais). João Alexandre Barbosa, autor do principal estudo a seu respeito, destaca (uma única vez em seu livro) que as linhas editoriais dos jornais em que o crítico atuou são importantes para a compreensão dos textos. O teor das críticas, afirma ele, "revela, simultaneamente, quer a linha do periódico em que foram editados, quer a espécie de público que procuravam atingir" (BARBOSA, 1974, p. 68). No entanto, Barbosa não chega a desenvolver essa análise, prendendo-se nas ideias apresentadas, sem conectá-las nem às linhas dos periódicos, nem a seus respectivos públicos.
} 
publicado A educação nacional, quando atuou como diretor de instrução pública no primeiro governo republicano do Pará, sob o comando de Lauro Sodré. O livro foi seu passaporte de ingresso nas rodas intelectuais de prestígio na capital.

No Rio, seu primeiro emprego foi no novíssimo Jornal do Brasil, criado em 9 de abril de 1891 por Rodolfo Dantas e que contava com Joaquim Nabuco como chefe de redação ${ }^{8}$. Em pouco tempo, por conta de uma equipe conceituada e das inovações que procurava implementar, desde o uso do telégrafo a novas formas de distribuição, com carroças (SODRÉ, 1999), o jornal se tornou um sucesso de público. A participação do crítico começou em 12 de julho de 1891 e sua estreia se deu com uma série de artigos justamente a respeito de questões educacionais. Embora em seu estado natal já escrevesse na imprensa sobre assuntos variados e notadamente sobre literatura, na capital ainda não era reconhecido como crítico literário (mas isso não tardaria a acontecer).

Na 20 de setembro de 1891, um domingo, Veríssimo publicou a sua primeira crítica literária no jornal no espaço do folhetim, no rodapé da primeira página (onde em geral o jornalista Constâncio Alves assinava a crônica política da semana com texto bem humorado). Na coluna intitulada Folhetim Literário, o texto tratava (com pouca simpatia) de um estudo histórico de Pereira da Silva sobre o poeta português Filinto Elísio. No domingo seguinte, em 27 de setembro, surgiu sua segunda coluna desse tipo, sobre o naturalista J. Barbosa Rodrigues, que o crítico qualificou como “o último indianista”. Mas o Folhetim Literário não voltou a ser publicado - sinal de que se tateava para encontrar o melhor caminho para a crítica literária.

Finalmente, em 5 de outubro, seguindo certamente o exemplo de Sainte-Beuve com suas Causeries du Lundi, o Folhetim ganhou o subtítulo “Às segundas-feiras”, naquele dia tratando do "naturalismo na literatura brasileira”, assinado por Veríssimo. Esse passaria a ser o formato adotado a partir de então para a sua crítica literária, sempre na primeira página e às vezes continuando no mesmo espaço na página 2. O tom parecia também mais ajustado à publicação que o das colunas iniciais. De alguma forma (ou pela forma), o crítico do romantismo francês se fazia influente ainda no Brasil na última década do século XIX.

O Jornal do Brasil aparentemente gostou do resultado, tanto que no dia 14 de outubro publicou na primeira página um grande agradecimento enviado por Alfredo E. Taunay elogiando a crítica de segunda-feira, 12 de outubro, sobre A retirada de Laguna, seu romance inspirado na Guerra do Paraguai. Taunay, que pertencia ao círculo de Nabuco, explicava no artigo o motivo de não ter escrito o livro em português, tecendo uma série de ressalvas ao mercado editorial brasileiro.

O ponto alto da atividade crítica de Veríssimo no Jornal do Brasil foi o texto que escreveu, em 6 de janeiro de 1892 (no início daquele ano deixaria logo de colaborar com

8 Nabuco inicialmente foi contratado como correspondente estrangeiro (outra iniciativa que o Jornal do Brasil usou com bastante sucesso de público, tendo correspondentes em diferentes países - sobre isso ver Sodré, 1999). Na época do lançamento do jornal, Nabuco morava em Londres, mas voltou ao Brasil em junho (como se pode ler no próprio jornal) e se integrou à redação criada por seu amigo Rodolfo Dantas. 
o jornal), sobre Quincas Borba, de Machado de Assis ${ }^{9}$, que, em sua opinião, era o maior escritor brasileiro de todos os tempos (e ele previa isso até para o futuro ${ }^{10}$ ). Os dois já haviam tomado distância dos projetos românticos, mas a possibilidade de uma crítica influente, aos moldes de Sainte-Beuve, mantinha-se um ideal. Em 8 de janeiro de 1900, Machado escreveu ao crítico (a correspondência entre eles é extensa) uma carta de uma única linha: "Meu caro Veríssimo, Sainte-Beuve qui pleure un autre Sainte-Beuve (Arsène Houssaye)” (2011) ${ }^{11}$. Seria uma brincadeira? Em todo caso, indica a permanência do crítico francês entre eles.

Em sua coluna na primeira página da Gazeta de Notícias, Machado chegou, inclusive, a comparar Veríssimo a Sainte-Beuve. Por ocasião da reedição em 1899 pela Laemmert de Cenas da vida amazônica, coletânea de novelas que o crítico lançara em 1886, quando vivia no Pará, Machado escreveu a crítica “Um livro”, na qual destacou: “O autor, que ocupa lugar eminente na crítica brasileira, também enveredou um dia pela novela, como Sainte-Beuve, que escreveu Volupté, antes de atingir o sumo grão da crítica francesa” (11 jun. 1899). Em 1909, foi a vez de Sílvio Romero relacionar o francês ao brasileiro no libelo destruidor (como era de seu estilo) Zéverissimações ineptas da crítica. Romero chamou o crítico paraense de "Sainte-Beuve peixe-boi” e ainda comparou as condições de trabalho entre eles:

Sainte-Beuve e Ed[mond] Scherer escreviam cada um seu artigo de crítica por semana; mas não colaboravam, ao mesmo tempo, em quatro ou cinco jornais, nem saíam para dar lições de livro aberto na Escola Normal, nem iam a agulheiro [a Garnier] algum. Eram robustos, tinham fortuna e secretários que os ajudavam (ROMERO, 1909, p. 52).

Se Veríssimo pode ser considerado um Sainte-Beuve dos trópicos, a julgar pelas comparações, estaria, no entanto, deslocado no tempo: seria um Sainte-Beuve anacrônico. Dez anos depois de sua chegada à capital, em 1901, quando escrevia a crítica literária no Correio de Manhã, já se mostrava saudoso dos anos iniciais do Jornal do Brasil. Por ocasião da morte precoce de Rodolfo Dantas, escreveu um artigo do qual se pode deduzir que vivia numa encruzilhada de estilos jornalísticos. Embora destacasse que a concepção inicial do Jornal do Brasil talvez não fosse “a mais consentânea com o tempo e o país” e

9 Com esse artigo, anunciou sua independência em relação ao programa crítico de Sílvio Romero (autor do monumental História da literatura brasileira, de 1888), ao destacar que o critério “nacionalístico” não podia ser decisivo para a análise das obras literárias, pois, se assim fosse, a literatura de Machado seria praticamente nula. O texto foi importante para sedimentar a ligação de Veríssimo com o escritor.

10 Em carta a Mário de Alencar que compõe o acervo da Academia Brasileira de Letras (ABL), ele afirmou, quando trabalhavam para preservar a memória do escritor, pouco tempo depois da morte deste: "E como eu creio que Machado de Assis será no século XXI um nome muito maior do que é hoje, tudo isso será precioso e a posteridade lhe será reconhecida meu caro Mário pela sua piedade para com ele" (ASSIS, [1908], 2011).

11 Tradução livre: "Sainte-Beuve que chora um outro Sainte-Beuve". Irene Moutinho, que trabalhou na reunião de cartas de Machado publicada pela Academia Brasileira de Letras (ABL), sob a coordenação de Sérgio Paulo Rouanet, escreve em nota que Houssaye (18151896), escritor e crítico francês, foi editor da prestigiada revista parisiense L'Artiste. Mas não se encontrou referência dessa frase em Houssaye. Segundo Moutinho, ela pode ter sido inventada por Machado (2011, p. 448). 
reconhecendo-se "suspeito" para falar a respeito, destacou que era a "mais digna, a mais elevada, a mais generosa”:

[...] ele [Dantas] não compreendia o jornal senão como órgão desinteressado de doutrina, um expositor não só de fatos, mas de princípios, de ideias, de sugestões teóricas e práticas que esclarecessem, guiassem, dirigissem as opiniões e vontades.

O jornal à americana era-lhe profundamente antipático; o escândalo jornalístico, sob qualquer forma, lhe era odioso, e para seguir a massa, ele não faria jamais um jornal. Queria-o mais, bem feito, bem escrito, respeitável pelo elenco da sua redação e pelo procedimento do próprio jornal (VERÍSSIMO, 1901).

Em outras palavras, pode-se dizer que o tipo de crítica defendida por Veríssimo, e pela qual era reconhecido, já encontrava dificuldade para se afirmar na cena jornalística. No próprio Correio, ele enfrentou dilemas, embora continuasse a escrever na primeira página, no espaço que o jornal chamava de "coluna nobre” (no alto à esquerda). Não se tratava de rodapé nem de folhetim, mas da parte reservada ao artigo de fundo, que revezava com outros articulistas, inclusive o proprietário, Edmundo Bittencourt. O jornal oposicionista criado em 1901 continuava a se basear na importância dos articulistas (a participação de Veríssimo foi algumas vezes enaltecida), mas o diário buscava uma linguagem mais popular para se firmar diante das novas camadas médias urbanas. A independência do crítico de certa forma entrou em choque com esses objetivos.

Em artigo no próprio Correio, escrito pelo poeta Antonio Salles por encomenda de Bittencourt $^{12}$, ele apresentou o crítico como “esse escritor, que não é um jornalista e, por sua índole e educação literária, jamais escreve sobre os joelhos” (06 jan 1903 - Grifos meus). Disse que os escritores contavam apenas com Veríssimo para a apreciação de seus livros, pois os dois outros críticos importantes, Sílvio Romero e Araripe Jr., não atuavam com tanta frequência nos jornais. No entanto, criticou de forma dura o que considerava ser uma falta flexibilidade por parte de Veríssimo nas suas análises. Poucas semanas depois, o crítico

12 A pesquisa realizada pelo autor deste artigo encontrou, na Fundação Casa de Rui Barbosa, carta de Edmundo Bittencourt em que ele encomenda a Salles que comente uma coletânea de artigos que havia sido lançada por Veríssimo. Os dois entretinham relações próximas e na carta o proprietário convida o poeta a se juntar a ele no fim de semana na serra. Depois da publicação do artigo, extremamente duro em relação a Veríssimo (possivelmente ainda mais duro que o libelo lançado contra ele em 1909 por Sílvio Romero, por seu tom menos anedótico), Bittencourt envia a Salles outra carta, em que o felicita pelo texto, dizendo concordar com tudo o que ele dissera. O artigo possui um tom editorializado, em que o uso da primeira pessoal do plural (um vago “nós”), expõe o desconforto do jornal em relação à independência de Veríssimo. Salles diz que Veríssimo era muito exigente para uma minguada literatura como a brasileira. Ele seria como o viajante que, acostumado a ver belos monumentos em grandes cidades civilizadas, se decepcionava diante da paisagem de uma pequena cidade provinciana, metáfora para a literatura brasileira. Bittencourt diz na sua carta: "Gostei muito do teu artigo: o Veríssimo é aquilo mesmo, e como é grande para o nosso meio!” (8 jan. 1903). Até de não patriota ele é acusado. Machado de Assis (outro "grande" do meio) se mostra solidário a Veríssimo no episódio, com muita delicadeza. A descoberta desse artigo e das cartas, não citadas ainda na fortuna crítica sobre Veríssimo, desvenda o motivo da saída do crítico do Correio da Manhã no início de 1903, algo que Broca (1956) tenta explicar, apontando outros motivos que não comprova. 
deixou o jornal (embora anos depois tenha voltado de forma esporádica, usando pseudônimo). Apesar de suas idas e vindas em jornais - como no importante Jornal do Commercio, com o qual colaborou de 1899 a 1901 (antes do Correio) e em outras ocasiões a seguir -, Veríssimo fez parte da primeira geração de críticos no país que conseguiu ter uma trajetória mais ou menos continuada na imprensa, como destaca Souza (2015).

Nos primeiros anos da República, os jornais começaram a apresentar um novo patamar de industrialização, o que beneficiou a atividade de críticos como Veríssimo, que não aceitava escrever por diletantismo e lutava pelo profissionalismo de sua atividade (sendo pai de numerosa família, contava ainda com o dinheiro da participação na imprensa para o orçamento).

A crítica literária, claro, já existia no Brasil antes desse tempo. No romantismo desempenhou papel fundamental. O próprio Machado fora crítico literário e chegou a escrever uma espécie de programa para a prática, intitulado “O ideal do crítico” (1865). No entanto, o Machado romancista e cronista sobrepõe-se ao crítico. Os críticos que vieram antes do período republicano não tiveram as condições de realizar obras extensas e com linhas programáticas plenamente desenvolvidas, conforme analisa Souza (2015).

O contraditório dessa situação, entretanto, é que no momento em que a crítica encontrou condições de se firmar como atividade continuada nos jornais brasileiros, estes já não ofereciam condições tão propícias para acolher a forma de articulação textual que ela propunha. Desse modo, a crítica literária vai se impor no país a partir de uma primeira relação de anacronia. Era um anacronismo entre o tipo de articulação textual que os críticos ainda buscavam impor - articulação textual oriunda da lógica do Romantismo - e a realidade da imprensa e do jornalismo na virada do século XIX ao XX. Isso pode ser ainda mais relevante se observarmos que a atividade crítica que se estabeleceu nesse período é tomada como a base de uma tradição de crítica literária no país, retomada continuamente muitas vezes ao longo do século XX.

A partir dos termos de Kittler (1990), pode-se dizer que, na virada do século XIX ao $\mathrm{XX}$, os jornais brasileiros buscavam se ajustar a uma ordem que começava a ficar distante daquela da "rede discursiva 1800", na qual o romantismo ocupava papel central. Em 1800, a crítica podia ser considerada uma tecnologia da letra: desempenhava um papel específico nos circuitos comunicacionais do período. Mas os tempos havia mudado: na "rede discursiva 1900”, a crítica literária, com sua carga hermenêutica, não era demandada do mesmo jeito. Para explicar o motivo dessa mudança, Kittler (1990) destaca o impacto que tecnologias como a do gramofone, do filme, da máquina de escrever e do telégrafo tiveram para criar novas demandas de articulação textual.

A literatura deixa aos poucos de ser central (há outros meios que permitem novas experiências de sentido, como a imagem e o som), mas não é propriamente a inovação que instaura imediatamente a mudança; com o telégrafo, tem-se um novo paradigma a respeito da articulação textual. No lugar da interpretação hermenêutica, que busca a profundidade de sentido, é a própria superfície textual que passa a ocupar papel central na rede discursiva. A 
invenção mesma da máquina de escrever, a partir do fim do século XIX, propicia uma nova relação com a escrita, que adquire certo distanciamento corporal com o uso da geringonça, inicialmente inventada para cegos (o que indica um automatismo). As experiências artísticas, do simbolismo ao expressionismo, vão nesse mesmo sentido, ao apontar a materialidade da linguagem em si (em seus jogos de linguagem), sem buscar a profundidade da interpretação pela hermenêutica, que se deixa de lado (embora isso não fosse uma regra totalizante e a hermenêutica tenha continuado em estudos históricos e/ou cada vez mais restrita a campos especializados do conhecimento).

Veríssimo pressentia que a crítica perdia espaço na imprensa e lutou contra isso. Criticava os jornais pelo que estavam se tornando e, em sua última colaboração mais alentada na imprensa, no Imparcial, a partir de 1912, tornou-se mais cronista político que crítico. Ele já não encontrava o mesmo espaço para impor sua crítica literária como nos anos anteriores. Para preservar sua proeminência no debate público, voltou-se mais para a política (embora sem abandonar a literatura que formava sua identidade). Julia Lopes de Almeida resumirá a mudança vivida no jornalismo em artigo para o mesmo Imparcial, quando afirmou que os jornais passavam “das ideias às massas”, as quais era preciso lisonjear (ALMEIDA, 1913, p. 2). Sem dúvida, o crítico preferia as ideias, como deixou claro no texto sobre o Jornal do Brasil, de 1891. Sua luta contra o novo jornalismo se expressou em embates pessoais. Em 1906, por exemplo, na primeira tentativa de ingresso de João do Rio na Academia Brasileira de Letras (ABL), pediu em carta ao amigo Oliveira Lima, “imortal” como ele, que não votasse no jornalista, “um simples repórter sem cultura” (23 maio 1906) ${ }^{13}$. Veríssimo era um dos fundadores da ABL, agremiação que nasceu em 1897 a partir dos encontros informais que ele propiciou na redação da Revista Brasileira, a qual ele fez reviver e dirigiu de 1895 a 1899. O crítico considerava João do Rio um arrivista, um cabotin, como disse ainda na carta de 1906 para desmerecê-lo.

Em O momento literário, de 1907, João do Rio, por sua vez, não poupou o crítico. Seria uma espécie de revanche? A obra pode ser lida como uma tentativa de contrapor a reportagem à crítica. Fazia sentido: numa sociedade na qual a literatura ocupava papel central no contexto cultural, a crítica literária era instância de grande prestígio nos jornais (possivelmente a mais prestigiada). Desse modo, para se afirmar, a reportagem precisava enterrar a crítica e ocupar esse lugar de destaque. É o que João do Rio busca fazer na enquete em que ouviu escritores sobre sua obra e relação com o jornalismo. No lugar da crítica, oferecia uma nova fórmula para compreender os escritores: a entrevista. Veríssimo foi convidado a participar, mas teria recusado, assim como Machado de Assis e alguns outros que cita. O jornalista apresenta

13 A carta compõe uma correspondência inédita que cobre cerca de 20 anos de amizade entre Veríssimo e o diplomata Oliveira Lima. O conjunto compreende 180 cartas e cerca de mil páginas manuscritas inéditas, transcritas por mim para a pesquisa cujo resultado apresentamos aqui parcialmente. O arquivo é preservado na Oliveira Lima Library, mantido na Universidade Católica da América, em Washington D.C., e integra uma das maiores coleções privadas de obras e documentos da cultura brasileira. Essa pesquisa maior contou no Brasil com bolsa da Capes, por meio do PPGCOM da UFRJ, e no exterior (em período sanduíche) com bolsa da Faperj, agências sem as quais não teria sido possível desenvolver o trabalho. Além disso, sem o apoio e o aceite da Universidade de Princeton (EUA), onde realizei o sanduíche, essa pesquisa não teria sido possível na maneira como se apresenta. 
desculpas razoáveis de todos, menos de Veríssimo, que teria dito que a entrevista era uma maneira de ganhar dinheiro à custa dos outros. No ataque à crítica, era também preciso atacar o principal crítico em atividade na imprensa na época, e Veríssimo sai ridicularizado no texto. Mas não apenas ele: o próprio Sainte-Beuve é apresentado como figura ultrapassada e caduca.

À pergunta sobre se o jornalismo seria "um fator bom ou mau para a arte literária”14, seu principal propósito ao consultar os cerca de 30 escritores, pode-se acrescentar se o jornalismo seria, no lugar da crítica, um bom ou mau fator... Já nas primeiras linhas da apresentação, em “Antes”, João do Rio afirma:

O público quer uma nova curiosidade. As multidões meridionais são mais ou menos nervosas. A curiosidade, o apetite de saber, de estar informado, de ser conhecedor são os primeiros sintomas da agitação e da nevrose. Há da parte do público uma curiosidade malsã, quase excessiva. Não se quer conhecer as obras, prefere-se indagar a vida dos autores. Precisamos saber? Remontamos logo às origens, desventramos os ídolos, vivemos com eles. A curiosidade é hoje uma ânsia... Ora, o jornalismo é o pai dessa nevrose, porque transformou a crítica e fez a reportagem. Uma e outra fundiram-se: há neste momento a terrível reportagem experimental. Foram-se os tempos das variações eruditas sobre livros alheios e já vão caindo no silêncio das bibliotecas as teorias estéticas que às suas leis subordinavam obras alheias, esquecendo completamente os autores. Sainte-Beuve só é conhecido das gerações novas porque escreveu alguns versos e foi amante de Mme. Vitor Hugo. Talvez apenas dele se recordem por ter essa senhora esquecido o gigante para amar o zoilo. Quem vos fala hoje, a sério, de Schlegel, de Hegel, ou mesmo do pobre Hennequin? A crítica atual é a informação e a reportagem (RIO, 1907 - Grifos meus).

No desfecho, volta a atacar seu alvo. No trecho “Depois”, no qual conclui os resultados do inquérito reproduzindo um suposto diálogo com um amigo imaginário, não há rodeios: "Meu amigo, eu acho que a crítica está absolutamente acabada”. As reflexões de Sainte-Beuve (mais uma referência ao crítico francês), os ensaios científicos ou metafísicos para explicar a composição da Comédia, de Dante, entre outros exemplos que cita, “desapareceram por completo”.

João do Rio é taxativo: “Hoje, sejamos francos, a literatura é uma profissão que carece do reclamo e que tem como único crítico o afrancesado Sucesso” (Grifos meus). O êxito de uma obra seria resultante de "uma força”, que não seria “cega”, destacou João do Rio, em metáfora que remete à ideia de Justiça e, portanto, àqueles que julgam, os quais, a exemplo dos críticos, deveriam ser “cegos” para serem justos. Essa “força” também não

14 Para um estudo sobre a atualização dessa pergunta um século depois ver Costa (2005). 
seria “inexplicável” e teria como base "leis fáceis de determinar”, o que pode ser tomado como outra contraposição à crítica, nem sempre fácil. As novas leis, ao contrário, seriam fáceis porque nascem da "notoriedade lucrativa” e do “valor de mercado" - e "a venda é uma força”. João do Rio expõe, desse modo, dilemas que já estavam sendo vivenciados por Veríssimo.

Não se trata, portanto, de situar a crise da crítica literária na imprensa somente a partir de meados do século XX no Brasil, como é mais comum afirmar. Desde a virada do século XIX para o XX, os jornais começam a expressar um desconforto e mesmo falta de espaço para o tipo de articulação textual que a crítica (oriunda do romantismo) propunha. O que viria a seguir já seria um desdobramento desse momento, digamos, fundador, o primeiro a propiciar - mesmo que anacronicamente - o exercício da crítica literária profissional de maneira mais continuada na imprensa.

\section{O rodapé}

A expressão “crítica de rodapé” se tornou, ao longo do século XX, quase sinônimo de crítica literária na imprensa. Isso a ponto de muitas vezes os estudos se referirem aos "rodapés de Veríssimo", como a "seu rodapé” sobre Os Sertões, de Euclides da Cunha15. Em 3 de dezembro de 1902, Veríssimo publicou o primeiro texto na imprensa sobre o livro, ocupando a metade da primeira página do Correio da Manhã. Foi uma de suas maiores críticas em jornal, com tom grandioso, mesmo que fizesse restrições à ênfase cientificista e à linguagem, com termos rebuscados que já naquele tempo estariam fora do uso corrente. Ainda assim, reconheceu o valor da obra, sua qualidade "nervosa e vibrante", e apontou a importância política e social do documento que denunciava o massacre de 1897 em Canudos. Com sua crítica, transformou o livro em imediato best-seller para os padrões da época; Euclides, desacreditado ao lançar o calhamaço, foi lançado à cena literária com triunfo. Mas a relação de Veríssimo com a obra não havia começado naquele momento, pois ele também havia apresentado o autor aos editores da Laemmert (em carta, Euclides se diz devedor do crítico desde o momento da assinatura do contrato) ${ }^{16}$. O livro se tornou, a partir da publicação, o principal título da tradicional casa editorial.

Em edições de aniversário, o Correio saudaria a crítica assinada por Veríssimo como um dos pontos altos de sua história. Nos anos 1940, Álvaro Lins se tornou “o titular”, como se dizia, da coluna de rodapé do Correio da Manhã. Era tido como o mais destacado do país e Drummond o via como “imperador da crítica literária” em seu tempo ${ }^{17}$. Lins declarou em inúmeras ocasiões e escritos que tomava como modelo José Veríssimo. Havia entre os dois, além disso, coincidências biográficas: ambos foram professores do Colégio

15 Nascimento e Facioli (2003) e Botelho (2004) afirmam que a crítica de Veríssimo foi publicada no “rodapé” do Correio da Manhã, o que não era o caso.

16 Ver Galvão e Galotti (1997).

17 Ele escreveu isso em crônica no Jornal do Brasil (6 jun. 1970), em homenagem a Álvaro Lins, em sua morte. 
Pedro II, possuíam origens provincianas (Veríssimo vinha do Pará e Lins de Pernambuco), integraram a ABL (com a qual se desentenderam), além de escreveram para o mesmo jornal. São semelhanças citadas por Bolle (1979, p. 57-58) que “devem ser encaradas não só como coincidência, mas como submissão voluntária a um modelo conscientemente escolhido”. É no crítico do início do século que Lins "se autoprojeta e de quem se sente e se quer herdeiro” (BOLLE, 1979, p. 57-58).

Desse modo, o que significaria, nos anos 1940, tomar como modelo um tipo de crítica que já em seu tempo, quase meio século antes, já começava a se mostrar de certo modo anacrônica em relação às demandas dos jornais?

A crítica de rodapé foi uma prática corrente no jornalismo na primeira metade do século passado (com apogeu na década de 1940). Diferenciava-se bastante da crítica do período anterior (de Veríssimo).

A coluna de Lins era publicada periodicamente no rodapé da página 2 do jornal, destacada dos suplementos em que intelectuais e críticos colaboravam. Integrava-se ainda, portanto, à “cabeça” do jornal (mas, sobretudo nos anos 1920 e 1930, os rodapés também eram publicados na primeira página e ainda podiam ser encontrados em diferentes páginas no jornal). Em todo caso, em linhas gerais, seriam a metamorfose do espaço do folhetim.

Identificados sobretudo à publicação dos romances seriados, os folhetins, como no caso do Jornal do Brasil, também acolhiam crônica, notas de bom humor e até crítica. No século XX, metamorfoseado em rodapé, torna-se espaço especializado da crítica - uma especialização que se definia em relação a outras especializações no jornal (isso embora seus detratores, os críticos universitários que começaram a se estabelecer em meados do século passado, quando as universidades se ampliavam, atacassem os autores de generalistas ou "bacharéis").

Autores como Barbosa (2007) e Meyer (1996) explicam parte dessa mudança, ao observarem que as notícias populares, de escopo sensacionalista, passaram a oferecer narrativas mais espetaculares que os próprios romances-folhetins, que deixaram de encontrar ressonância junto ao público. Mas por que o quadrilátero do folhetim, largado o romance, vai a se tornar cativo da crítica? O espaço antes dedicado ao romance passa a ser dominado pela crítica do romance: há uma dança das cadeiras. Ali circunscrita, delimitada a cercados, a crítica não conseguia mais “abrir suas asas” como aconteceu em 1902 no texto sobre Os Sertões.

Pode-se dizer que esse “cercado” foi um subterfúgio de sobrevivência, uma adaptação às demandas industriais dos jornais, que buscavam novas formas de divisão do trabalho, tendo como base a reportagem. Seria, de uma certa maneira, uma crítica mais instrumentalizada. Antonio Candido, ao contar como se tornou foi crítico de rodapé em 1943 na Folha da Manhã, em São Paulo, mostra-se bem mais adaptado ao ritmo da reportagem que no tempo de Veríssimo. Quando começou, não tinha experiência de crítica e nem formação em literatura. 
A minha formação o que foi? Era a coisa que o jornalista, o foca, que é jogado e fala: 'Você tem que escrever sobre o escândalo no Senado'. E tem que escrever! Eu aceitei a tarefa de escrever sobre os livros da semana. Cinco laudas datilografadas com dois espaços, 30 linhas e 70 toques (RODRIGUES, 2011, p. 240).

Eram profissionais, portanto, mais circunscritos dentro do espaço do jornal que os críticos da fase anterior. Isso embora ainda desfrutassem de grande prestígio. De certa maneira, mesmo mais afeita ao ritmo industrial e com uma forma de articulação textual diversa daquela da crítica de matriz romântica (a começar pela delimitação do espaço), foi uma crítica que ainda se inspirava e buscava modelos no período anterior (como é evidente para o caso de Álvaro Lins, referência entre os críticos de seu tempo). Nesse processo, podese dizer que há uma espécie de acúmulo de camadas de anacronia (um certo desajuste) da atividade crítica em relação ao jornalismo. Essas camadas teriam como base uma esfera memorável da crítica, acionada por seus praticantes como força de uma tradição que reivindicavam com o objetivo de afirmar no cotidiano a sua atividade e relevância.

\section{Brevíssimas considerações finais}

Na crítica de rodapé, ainda sobrevivia algo do folhetim e da forma de articulação textual predominante nos jornais do século XIX. Sinal disso é que o rodapé não irá sobreviver aos anos 1950, um período de intensa modernização no jornalismo no Brasil, quando se aprofunda, como projeto geracional, a reportagem como marca de identidade (RIBEIRO, 2007). Esse processo se reflete no desenvolvimento industrial dos mercados jornalísticos no Brasil e os profissionais procuram varrer da cena de trabalho o que chamam de "literatices". Assim, também a crítica que guardava uma certa fonte na matriz romântica parece se desvanecer.

De certa forma, ganha força nesse momento, em meados do século XX, a clivagem apontada no início do século XX por João do Rio, entre a crítica e a reportagem. São distintas formas de articulação textual que se entrechocam e, dentro dos jornais, a reportagem parece sair vencedora.

Ocorre em relação à crítica o que se pode chamar de processo de construção mítica, procedimento que se repete com frequência no universo do jornalismo, conforme observa Barbosa (2007, p. 80), “instaurando um momento de glórias e virtudes, em contraposição a um presente onde todos os valores existentes anteriormente se perderam”. Por força das transformações na imprensa, a crítica mudou na forma, mas a compreensão que se tinha dela não variou na mesma velocidade. Foi aberto o caminho para um distanciamento entre sua compreensão, idealizada com base na memória, e a realidade que se oferecia para sua 
expressão. Duas camadas de práticas profissionais, portanto, foram se sobrepondo: uma memorável, outra possível. O efeito foi muitas vezes um sentimento nostálgico.

O processo de reinvenção e metamorfose de linguagens dentro do jornalismo, entretanto, é incessante. Teria a crítica sobrevivido de alguma forma encoberta, em algumas práticas jornalísticas, como a do chamado jornalismo cultural, que ao se propor a realizar a reportagem das criações artísticas, acaba de certa forma reeditando instâncias da crítica? (A crítica estaria atuando sob nova roupagem ou como o prisioneiro, que, para não chamar a atenção de si, finge-se de morto?) As configurações que se experimentam nos ambientes digitais certamente acrescentarão novos capítulos a esse debate.

\section{Referências}

ALMEIDA, J. L. Os jornais de hoje (artigo de jornal). O Imparcial, p. 2. Rio de Janeiro: 17 jan. 1913.

ASSIS, M. Correspondência de Machado de Assis: tomo III, 1890-1900. Coordenação e orientação Sergio Paulo Rouanet; reunida, organizada e comentada por Irene Moutinho e Sílvia Eleutério. Rio de Janeiro: ABL, 2011.

BARBOSA, J. A. A tradição do impasse: Linguagem da crítica \& crítica da linguagem em José Veríssimo. São Paulo: Ática, 1974.

BARBOSA, M. História cultural da Imprensa: Brasil 1800-1900. Rio de Janeiro: Mauad X, 2010.

BARBOSA, M. História cultural da Imprensa: Brasil 1900-2000. Rio de Janeiro: Mauad X, 2007.

BARBOSA, M. Imprensa, poder e público. Os diários do Rio de Janeiro, 1880-1930. 1996. Tese (Doutorado em História). Programa de Pós-Graduação em História/ Instituto de Ciências Humanas e Filosofia, da Universidade Federal Fluminense (UFF), Niterói.

BOLLE, A. B. M. A obra crítica de Álvaro Lins e sua função histórica. Petrópolis: Vozes, 1979.

BOTELHO, A. Crime e expiação: a recepção de 'Os Sertões' de Euclides da Cunha. Revista Brasileira de Ciências Sociais, v. 19, n. 54, 2004.

BROCA, B. A vida literária no Brasil - 1900. Rio de Janeiro: Editora José Olympio, 1956.

CANDIDO, A. A formação da literatura brasileira: Momentos decisivos 1750-1880. Rio de Janeiro: Ouro sobre Azul, [1957] 2006.

COSTA, C. Pena de aluguel: escritores jornalistas no Brasil 1904-2004. São Paulo: Companhia das Letras, 2005.

GALVÃO, W. N.; GALOTTI, O. (orgs.). Correspondência de Euclides da Cunha. São Paulo: Editora da Universidade de São Paulo (Edusp), 1997.

GUMBRECHT, H. U. Media History as the Event of Truth: On the singularity of Friedrich A. Kittler's Works, Afterword. In: KITTLER, F. The truth of the technological world. Traduzido por Erik Butler. Stanford University Press: Stanford, Califórnia, 2013.

GUMBRECHT, H. U.; PFEIFFER, L. (orgs). Materialities of Communication. Stanford: Stanford University Press, 1994. 
KITTLER, F. Discourse Networks, 1800/1900. Traduzido por Michael Metteer com Chris Cullens. Prefácio de David Wellbery. Stanford University Press: Stanford, Califórnia, 1990.

MARQUES DE MELO, J. A opinião no jornalismo brasileiro. 2a ed. rev. Petrópolis: Vozes, 1994.

MEYER, M. Folhetim. Uma história. São Paulo, Companhia das Letras, 1996.

NASCIMENTO, J. L.; FACIOLI, V. (orgs.). Juízos críticos - ‘Os Sertões’ e os olhares de sua época. São Paulo: Nankin Editorial: Editora Unesp, 2003.

PRENDERGAST, C. The classic: Sainte-Beuve and the Nineteenth-Century Culture Wars. Oxford University Press: Nova York, 2007.

RIBEIRO, A. P. G. Imprensa e História no Rio de Janeiro dos anos 1950. Rio de Janeiro: E-papers, 2007.

RIO, J. O momento literário, inquérito (1907). Obra em domínio público. Disponível em: http://www. dominiopublico.gov.br. Acesso em: 26 ago. 2016.

RODRIGUES, J. F. Nas páginas do jornal - Ángel Rama e Antonio Candido: críticos literários na imprensa. Tese de Doutorado. Universidade de São Paulo, 2011.

ROMERO, S. Zéverissimações ineptas da crítica (Repulsas e desabafos). Porto: Oficinas do "Comércio do Porto”, 1909. [Disponível em Brasiliana da Universidade de São Paulo (USP): http://www.brasiliana.usp. br/handle/1918/01616600\#page/1/mode/1up. Acesso em: 05 ago. 1916].

SODRÉ, N. W. História da Imprensa no Brasil. 4a ed. (atualizada). Rio de Janeiro: Mauad, 1999.

SOUZA, R. A. Variações sobre o mesmo tema: ensaios de crítica, história e teoria literárias. Chapecó, SC: Argos, 2015.

VERÍSSIMO, J. História da literatura brasileira: de Bento Teixeira (1601) a Machado de Assis (1908). 7a ed. Rio de Janeiro: Topbooks, 1998.

VERÍSSIMO, J. Rodolpho Dantas (artigo de jornal). Correio da Manhã, p. 1. Rio de Janeiro: 16 set. 1901.

\section{Acervos de periódicos da Fundação Biblioteca Nacional:}

Correio da Manhã

Gazeta de Notícias

Jornal do Brasil

Jornal do Commercio

O Imparcial

\section{Manuscritos originais:}

Correio da Manhã

Gazeta de Notícias

Jornal do Brasil

Jornal do Commercio

O Imparcial 


\section{Rachel Bertol}

Professora no Departamento de Comunicação Social da Universidade Federal Fluminense (UFF) e no Programa de Pós-Graduação em Mídia e Cotidiano (PPGMC) da mesma instituição. Doutora em Comunicação e Cultura pela UFRJ, com Doutorado Sanduíche na Universidade de Princeton (EUA). E-mail: rachelbertol@gmail.com.

Recebido em: 03.07.2017 Aprovado em: 24.09.2019 